Review

\title{
Radionuclide Imaging of Neurohormonal System of the Heart
}

\author{
Xinyu Chen ${ }^{1,2}$, Rudolf A. Werner ${ }^{1,2}$, Mehrbod S. Javadi³, Yoshifumi Maya ${ }^{1}$, Michael Decker ${ }^{4}$, Constantin \\ Lapa $^{1}$, Ken Herrmann ${ }^{1}$, Takahiro Higuchi ${ }^{1,2}{ }^{凶}$ \\ 1. Devision of Nuclear Medicine, University Hospital of Wuerzburg, Wuerzburg, Germany. \\ 2. Comprehensive Heart Failure Center, University Hospital of Wuerzburg, Wuerzburg, Germany. \\ 3. Devision of Nuclear Medicine, Johns Hopkins Bayview Medical Center, Baltimore, MD, USA. \\ 4. Institute of Pharmacy and Food Chemistry, University of Wuerzburg, Wuerzburg, Germany.
}

$\triangle$ Corresponding author: Takahiro Higuchi, Universitaetsklinikum Wuerzburg, Klinik und Poliklinik fuer Nuklearmedizin, Zentrum fuer Innere Medizin (ZIM), Haus A4, Oberduerrbacher Str. 6, 97080 Wuerzburg. Tele: +49-931-20135455 Mob: +49-15787813788 Fax: +49-931-201634000 E-mail: Higuchi_T@klinik.uni-wuerzburg.de, thiguchi@me.com.

(C) 2015 Ivyspring International Publisher. Reproduction is permitted for personal, noncommercial use, provided that the article is in whole, unmodified, and properly cited. Please see http://ivyspring.com/terms for terms and conditions.

Received: 2014.10.24; Accepted: 2015.01.02; Published: 2015.02.15

\begin{abstract}
Heart failure is one of the growing causes of death especially in developed countries due to longer life expectancy. Although many pharmacological and instrumental therapeutic approaches have been introduced for prevention and treatment of heart failure, there are still limitations and challenges. Nuclear cardiology has experienced rapid growth in the last few decades, in particular the application of single photon emission computed tomography (SPECT) and positron emission tomography (PET), which allow non-invasive functional assessment of cardiac condition including neurohormonal systems involved in heart failure; its application has dramatically improved the capacity for fundamental research and clinical diagnosis. In this article, we review the current status of applying radionuclide technology in non-invasive imaging of neurohormonal system in the heart, especially focusing on the tracers that are currently available. A short discussion about disadvantages and perspectives is also included.
\end{abstract}

Key words: Heart failure, cardiac neurohormonal system, nuclear cardiology, SPECT, PET, radiotracer.

\section{Introduction}

Benefiting from great advances in molecular biology, the understanding of cardiovascular diseases including heart failure (HF) has dramatically improved at genomic, transcriptional and proteomic levels. They have led to the discovery of promising experimental strategies for prevention, diagnosis and treatment of cardiovascular disease as well [1]. Among them, molecular imaging using radionuclide techniques focuses on small scale molecular events rather than anatomical alterations (such as in computed tomography (CT), ultrasound, radiography). The molecular imaging provides non-invasive method for the monitoring of functional changes in indi- vidual organs, with higher sensitivity, specificity and the possibility of quantification of these alterations. In addition, the rational design of radiotracers makes it feasible to bring forth valuable pathophysiological information in patients, as well as references and guidelines for clinical treatment. Single photon emission computed tomography (SPECT) and positron emission tomography (PET) are well established for clinical use for evaluating global and regional myocardial functional information at the molecular levels [2]. The advantages and challenges of using molecular imaging are: detection of early and treatable stages of disease; stratification of disease severity; prediction of 
disease progression; monitoring of treatment efficacy and optimization of therapeutic strategies [1]. Neurohormonal model instead of hemodynamic disorder has received more and more attention recently, which has led to the clinical applications of therapeutics targeting sympathetic and renin angiotensin system (RAS). Neurohormonal activation is considered as compensatory mechanism in HF and maintains perfusion to the heart, yet in the meanwhile is also responsible for the progression of HF [2]. From long-term point of view, it is associated with progressive impairment of ventricular function and symptoms of HF [3]. For the last few decades, several molecular imaging applications targeting neurohormonal system have been developed and utilized clinically. Yet at the same time, there are still challenges, which must be met before the true potential of personalized medicine can be fully achieved [4]. Despite their critical role in regulation of heart, local neurohormonal statuses of patients are not routinely and closely monitored in clinical practice. Beta blockers, angiotensin-converting enzyme (ACE) inhibitors and angiotensin receptor blockers are clinically applied to regulate the neurohormonal levels, but further utilization guidance and dosage recommendation should be in depth investigated $[5,6]$. So far, there is no ideal radiotracer available that can accurately reflect the overall function of neurohormonal systems. Therefore, in order to give the readers a brief touch and concise overview of the development of neurohormonal imaging, we will mainly review the latest advances in non-invasive cardiac radioactive tracers designed to evaluate pathophysiological functions, to enable diagnosis and indication for therapeutic applications along with the discussion of their advantages and shortcomings.

\section{Physiopathological basis for heart failure imaging}

$\mathrm{HF}$ is a common clinical syndrome, in which left ventricular dysfunction triggers compensation via neurohormonal activation in order to restore cardiac output. These responses become part of the disease process leading to a vicious and lethal circle. HF is caused by many different diseases that damage cardiac structure and functions, e.g. coronary heart disease (CHD), hypertension, diabetes etc. Physiologically, the heart is regulated and controlled by many different neural and hormonal systems, including the automatic nervous system, RAS, endothelins, and atrial natriuretic peptide (ANP). The neurohumoral system is an attractive target for therapeutic investigations [7]. In patients with $\mathrm{HF}$, the decreased cardiac output results in an activation of high-pressure baroreceptors in the heart and blood vessels, which further triggers changes in heart rate and efficiency through the reflex and regulation of the sympathetic nervous system [8]. Moreover, the RAS system is activated due to decreased blood flow in the kidney, which is caused by reduced pump function. It is characterized by the release of renin and the eventual conversion into angiotensin II catalyzed by ACE. Angiotensin II is involved in sodium and water retention as well as vascular constriction [9]. These activations are compensatory mechanisms at the early stage of HF to maintain cardiac output; however they also play a critical role in the aforementioned vicious circle of advanced HF by increasing myocardial energy consumption, afterload and arrhythmias.

The traditional focus of evaluation and management of HF has been on hemodynamic abnormalities caused by decreased cardiac output. Much of the current attention in research and clinic has turned to neurohormonal and molecular pathophysiology. These efforts are not only to identify patients with abnormal cardiac function, but also and more importantly those "potential" patients who have not yet to present with pathologic physiology [10].

Currently, medications against HF mainly employ the following strategies: Beta-adrenoreceptor blockade, ACE inhibition, angiotensin II receptor type $1\left(\mathrm{AT}_{1}\right)$ blockade as well as non-pharmacological therapy using electrical devices. These show clinical evidence in reducing mortality and morbidity in HF patients $[11,12]$. Beta-blockers antagonize the effects of endogenous catecholamines, such as epinephrine and norepinephrine (NE), in overall sympathetic nervous system, and slow down nerve impulses and workload. The main beta-blockers used clinically are beta1-blockers due to their predominant distribution in the heart. Blockage leads to clinical benefits by counteracting the overt noxious effects of increased catecholamines level through compensatory feedback, while consequently improving survival rates and even reversing pathologic cardiac remodeling. However, it is worth mentioning that the clinical effects and therapeutic responses of beta-blockers in patients may vary greatly due to age and racial differences (i.e. genetic variations) $[13,14]$. In addition, both $\mathrm{ACE}$ inhibitors and $\mathrm{AT}_{1}$ antagonists are used clinically and have also generated successful results in hypertension, HF and post-myocardial infarction. Especially the "sartan" (angiotensin receptor blocker) series of compounds, such as losartan and valsartan, seem to be superior to ACE inhibitors and may offer extra benefits with fewer side effects [15].

It is noteworthy that these medications do not always lead to positive effects in HF patients because of dose related side effects. Therefore, to maximize the benefits of these available therapies, patients at a high 
risk of death, such as pump failure and sudden cardiac death (SCD), require accurate risk stratification. Personalized evaluation of autonomic nervous function with non-invasive imaging methods is necessary and urgent, as this information could not only improve pathophysiological understanding of $\mathrm{HF}$ at the individual level, but also to serve as prognostic indicator of therapy applications.

\section{Sympathetic nervous imaging}

The autonomic nervous system is composed of two limbs: sympathetic and parasympathetic, where the former one uses NE as the main neurotransmitter and the latter acetylcholine. The sympathetic nervous system exerts positive inotropic effects, whereas the parasympathetic nervous system applies negative inotropic effects and chronotropic effects. Sympathetic neurons are widely distributed in the human heart, globally in the myocardium and especially in the coronary vessels. NE is produced in presynaptic neurons, using tyrosine as starting resource through dihydroxyphenylanaline and dopamine as intermediates (Figure 1). It is transported into the presynaptic neuronal terminal vesicles via energy requiring vesicular monoamine transporter (VMAT). The firing impulse at the presynaptic neuron leads to the activation of voltage-dependent calcium channels and vesicles containing NE are released into the synaptic cleft

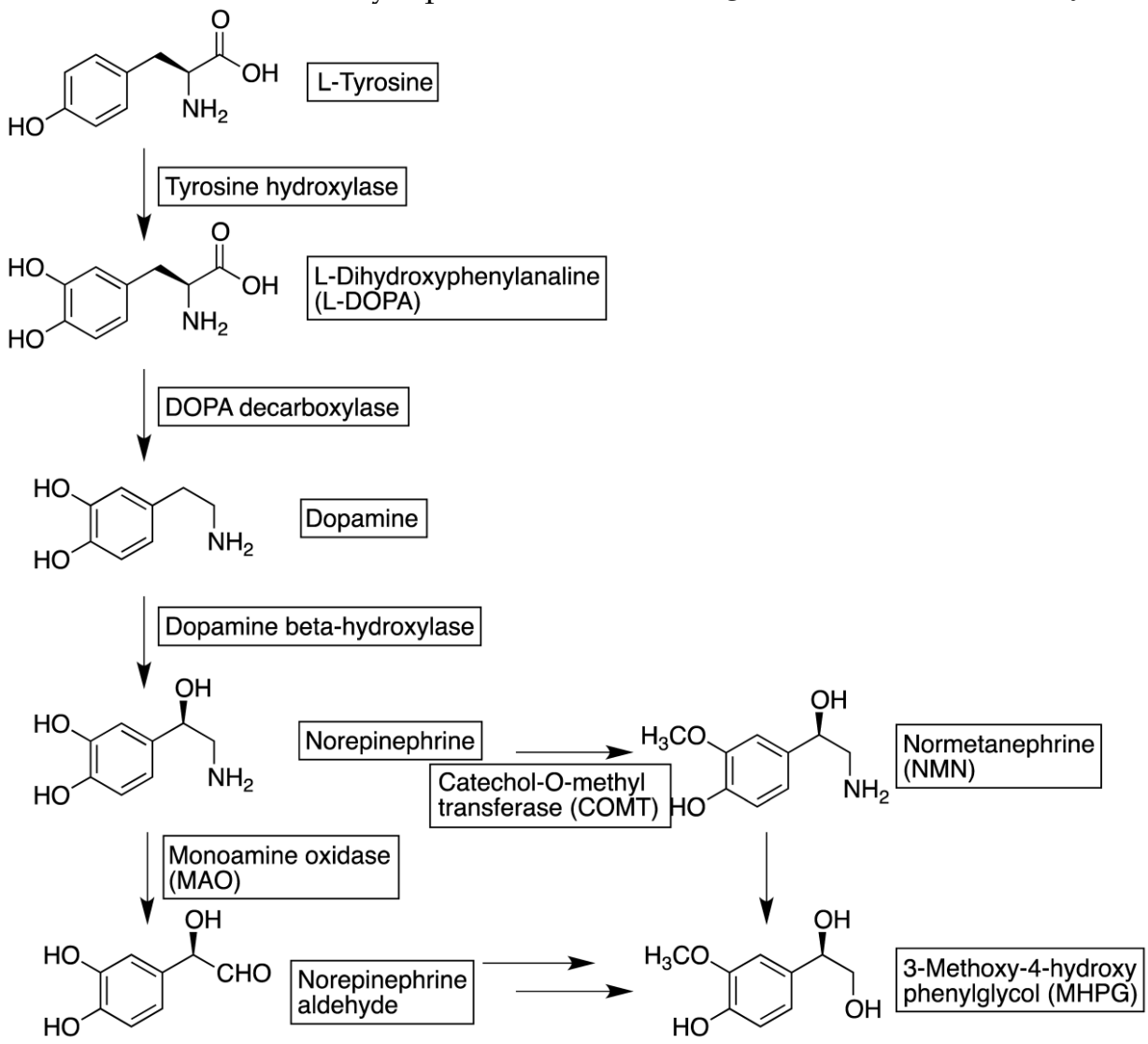

via exocytosis. Only a minority of the neurotransmitter binds to the adrenoreceptors (including alpha- and beta-adrenoreceptors) for downstream effects, whereas the majority of NE is selectively reabsorbed into presynaptic neurons via the uptake- 1 transporter. The uptake-1 mechanism is both energy and sodium concentration dependent. At least $94 \%$ of the reabsorbed NE is restored again into releasing-vesicles while the remainder is metabolized by monoamine oxidase (MAO) and released into systematic circulation for further metabolic processing [16]. In addition to uptake-1, there is a second reuptake mechanism mediated by the so-called "uptake- 2 transporter". The uptake-2 mechanism is dominant in non-neuronal tissues, for instance cardiocyte and vascular endothelial cells [17]. The procedure is crucial especially in ATP depletion situations such as ischemia, simply due to the fact that uptake- 2 is, unlike uptake-1, energy and sodium concentration independent. NE is, after the uptake-2 mechanism, metabolized into 3-methoxy-4-hydroxyphenylglycol (MHPG) via normetanephrine (NMN) by catecholamine-O-methyl-transferase (COMT) and MAO. Besides neuronal reuptake, there are also a number of other regulatory mechanisms controlling the release and termination of NE; in particular the alpha2-adrenoreceptor at the presynaptic neuron provides negative feedback for exocytosis. 
<smiles>N=C(N)NCc1cccc(Br)c1</smiles>

123|-MIBG<smiles>C[NH2+]C[C@H](O)c1ccc(O)c(O)c1</smiles><smiles>N=C(N)NCc1ccc(OCCCF)c(Br)c1</smiles><smiles>CN[C@@H](C)[C@H](O)c1cccc(O)c1</smiles><smiles>CNCC(O)c1cccc(O)c1</smiles><smiles>N=C(N)NCCc1ccc(F)c(O)c1</smiles>

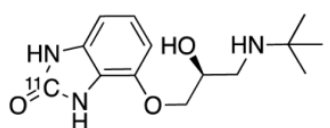

${ }^{11 C-C G P 12177 ~}$

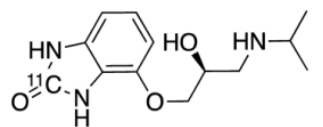

${ }^{11} \mathrm{C}-\mathrm{CGP} 12388$

Figure 2. Chemical structures of reviewed cardiac radiolabelled tracers in sympathetic nervous system.

Several radiolabeled tracers have been developed to investigate the sympathetic nervous system [18]. Catecholamines and their analogs are applied in both SPECT and PET applications, in which they follow the same metabolic cascade and therefore providing valuable information regarding pathophysiologic catecholamine turn over states at presynaptic level. More importantly, analogs of these neurotransmitters, which are resistant to certain steps of metabolism, can be used to monitor these specific steps.

$m$-Iodobenzylguanidine (MIBG, Figure 2) is a structural analog of NE and was originally developed by Wieland and coworkers as a radiotracer for scintigraphic imaging studies of adrenergic tumors [19]. It is, however, currently also used as a SPECT tracer for myocardial sympathetic innervation. Because of its relatively specific neuronal extract through uptake-1 mechanism by presynaptic neurons and accumulation in storage vesicles it is also used to monitor presynaptic functions. ${ }^{123}$ I-MIBG itself does not show pharmacological activity, neither by activating the postsynaptic alpha- or beta-adrenoreceptors nor by binding presynaptic alpha2 receptor. MIBG is resistant to metabolic enzymes (i.e. MAO and COMT) that are responsible for the metabolism of endogenous neurotransmitters. Therefore, uptake of ${ }^{123}$ I-MIBG in patients with HF reflects equilibrium between the capacity of storing ${ }^{123}$ I-MIBG in the presynaptic neuron and of release into the synaptic cleft. Regional myocardial distribution of ${ }^{123}$ I-MIBG shows a clear early phase (15 to 30 minutes) initial uptake and delayed retention (3-4 hours) with regard to the heart to mediastinum ratio, which is basically a measure of washout rate. Decreased uptake and retention of 123I-MIBG may represent increased release of NE from presynaptic neuron endings, deterioration of uptake-1 transporter (due to, for instance, ATP exhaustion), decreased density of sympathetic nerve ending, or competition with NE (higher concentration of it in synaptic cleft). Depending on these possibilities, a cardiovascular condition can be suggested accordingly. The ADMIRE-HF study confirmed the independent prognostic value of ${ }^{123}$ I-MIBG imaging in patients with NYHA class II and III HF [20]. Negative predictive value of cardiac death at 2 years in patients with preserved MIBG cardiac uptake was $98.2 \%$.

One clinical application of 123I-MIBG imaging was to identify patients who would benefit most from an implantable defibrillator [21, 22]. In a study involving 106 patients with chronic HF, 18 of them died during the follow-up period (65 \pm 31 months) due to SCD, which strongly correlated to the wash out value of ${ }^{123}$ I-MIBG obtained from MIBG imaging [23]. This is a useful predictor of SCD in patients with mild to moderate chronic HF and at risk of ischemic coronary artery disease, who are therefore in great need to be treated with an implantable cardiac defibrillator (ICD), independently of left ventricular ejection fraction (LVEF). While enrolling $160 \mathrm{HF}$ patients referred for ICD therapy, cardiac sympathetic denervation as assessed by MIBG can be used to predict ventricular arrhythmias and lethal conditions [24]. As a result of this, it is possible to prevent those patients who are in a need of ICD being overlooked and vice versa who do not need the implantation suffering from surgery and high cost [25].

A study was performed by Merlet et al., which included 112 patients with HF resulting from idiopathic dilated cardiomyopathy. Within all the factors the patients underwent, MIBG uptake is the only independent one strongly correlated with cardiac mortality during follow-up [26]. In another study involving 93 patients with chronic HF, planar MIBG imaging was performed. The late uptake of MIBG as well as peak oxygen consumption turned out to be a critical 
predictor of death or heart transplantation and could be used as prognostic indexes [27]. A further study reconfirmed the direct correlation between late uptake of MIBG and the number of non-survivors [28]. Moreover, the myocardial washout rate of MIBG is one of the best predictors of cardiac death and should be taken into consideration for prognosis in patients with chronic HF. Those patients with high washout rate showed a higher chance to develop into more severe conditions or cardiac death [23, 29-31]. In summarizing all above factors, a multicenter study including eighteen studies with totally 1755 patients was performed. The result further confirmed that decreased late heart mediastinal ratio or increased myocardial MIBG washout are independently associated with the development of worse prognosis [32]. It is noteworthy, although MIBG has shown potential to predict possible lethal conditions and help determining the application of ICD or cardiac transplantation, studies based on larger population as well as applying standardized procedures and criteria should be performed.

Although MIBG has been used and studied for 30 years, information is still missing especially with regard to drug interference. A study showed that a variety of drugs interact with MIBG uptake by five mechanisms: uptake-1 inhibition, competition or inhibition of active transport to vesicles (by VMAT), depletion of neurosecretory vesicle content and calcium-mediated mechanism. It is therefore recommended to pay attention when clinical studies are performed, in order to avoid potential bias and to improve the efficacy of MIBG scintigraphy as diagnostic tool [33].

The ephedrine analog ${ }^{11} \mathrm{C}$-meta-hydroxyephedrine $\left({ }^{11} \mathrm{C}-\mathrm{HED}\right.$, Figure 2) [34] shares similarities to 123I-MIBG: targeting sympathetic nerve terminals with a similar metabolic profile to NE [35]. It is transported to the neuronal terminus mostly via the uptake- 1 mechanism, and is resistant to MAO and COMT metabolism. However, instead of storing in vesicles like ${ }^{123}$ I-MIBG, the retention of ${ }^{11} \mathrm{C}-\mathrm{HED}$ in the myocardium mainly reflects a continuing release and reuptake, which allows the quantification of retention fraction in myocardial tissue against the arterial input function. ${ }^{11} \mathrm{C}-\mathrm{HED}$ is one of the most popularly studied sympathetic nerve PET tracers in human studies. Besides the advantages a PET tracer can offer, i.e. superior spatial resolution and sensitivity, the concentrations of ${ }^{11} \mathrm{C}-\mathrm{HED}$ in blood and myocardial tissue as well as the changes over time can also be quantified [36].

A study was performed in a group of 21 patients to determine whether ${ }^{123}$ I-MIBG imaging-derived parameters such as heart-to-mediastinum uptake ratio or washout rate are associated with quantitative parameters achieved from ${ }^{11} \mathrm{C}-\mathrm{HED}$ PET. A direct comparison between ${ }^{123}$ I-MIBG SPECT and ${ }^{11} \mathrm{C}-\mathrm{HED}$ PET with regard to image quality, defect size as well as location was also investigated. The results clearly showed that applying ${ }^{11} \mathrm{C}-\mathrm{HED}$ could generate better tomographic imaging. In addition, 123I-MIBG heart-to-mediastinum uptake ratio gives a reliable estimate of cardiac sympathetic innervation as measured by ${ }^{11} \mathrm{C}$-HED PET. Furthermore, despite the close correlation in defect size, ${ }^{11} \mathrm{C}$-HED PET appears to be more suitable for assessing regional abnormalities than 123I-MIBG SPECT because of better quality images yielded [35].

Additional sympathetic innervation tracers evolved from native neurotransmitters include ${ }^{11} \mathrm{C}$-epinephrine (EPI) and ${ }^{11} \mathrm{C}$-phenylephrine (PHEN, Figure 2). Although they are both easily metabolized by MAO degradation, they still allow assessment of both neuronal uptake and vesicular storage using PET. Inhibition of MAO results in an increase in myocardial ${ }^{11} \mathrm{C}-\mathrm{PHEN}$ retention, which makes it an option to examine in vivo MAO activity [37]. However, due to the unspecific leaking of ${ }^{11}$ C-PHEN from vesicular storage, it is not sensitive to use as a tracer reflecting kinetic progress in heart [38]. A clinical study involving 7 healthy volunteers and 10 transplant patients was performed to investigate tracer behavior after heart transplantation. Both ${ }^{11} \mathrm{C}-\mathrm{HED}$ and ${ }^{11} \mathrm{C}$-EPI showed high selectivity for neuronal uptake in the heart, but with a significant reduction of tracer retention in transplant recipients. Furthermore, due to the resistance of ${ }^{11} \mathrm{C}-\mathrm{HED}$ to metabolic breakdown, its retention behavior reflects more on the presynaptic nerve terminal uptake- 1 mechanism, while ${ }^{11} \mathrm{C}$-EPI and ${ }^{11} \mathrm{C}$-PHEN also depend on other factors [39].

Overall, the application of ${ }^{11} \mathrm{C}-\mathrm{HED}$ gave similar information as those applying ${ }^{123}$ I-MIBG due to comparable mechanisms, since both reflect autonomic functions of the heart. However, ${ }^{11} \mathrm{C}-\mathrm{HED}$ PET produces improved image quality, the possibility of quantification, temporal and spatial resolution when compared to the application of 123 I-MIBG in SPECT. On the one hand, it is superior to use PET imaging due to the reasons mentioned above, on the other hand, it should be emphasized that the costs for PET imaging are much higher than SPECT because of the on-set requirement of cyclotron for generating ${ }^{11} \mathrm{C}$ isotope. The short half-life of ${ }^{11} \mathrm{C}$ (merely 20 minutes) greatly limits its clinical use. Nevertheless, a novel ${ }^{18} \mathrm{~F}-$-labeled PET tracer, ${ }^{18} \mathrm{~F}-\mathrm{L}$ MI1195 (Figure 2) has been recently developed and reported [40]. In comparison to ${ }^{11} \mathrm{C}$ PET tracers, ${ }^{18} \mathrm{~F}$ tracers provide several advantages: these include a longer radioactive 
half-life of approximately 110 minutes, distribution from a central cyclotron facility, and higher flexibility in the design of synthetic scheme and study protocols with delayed or prolonged imaging. Cardiac PET imaging with ${ }^{18} \mathrm{~F}-\mathrm{L} M \mathrm{I} 1195$ in rats, rabbits and nonhuman primates revealed myocardial uptake with low radioactivity levels in the blood, lungs and liver. In rabbits pretreated with desipramine, myocardial uptake decreased in a concentration dependent manner. In nonhuman primates pretreated with desipramine, uptake of ${ }^{18} \mathrm{~F}-\mathrm{L}$ MI1195 in myocardium also decreased by $66 \%$ [40]. In addition, ${ }^{18}$ F-LMI1195 is retained in the heart of rabbits primarily via the neuronal uptake- 1 mechanism and is selectively associated with the NE transporter, similar to ${ }^{123}$ I-MIBG. Therefore, this tracer can be used for evaluation of cardiac sympathetic denervation and guidance of antiarrhythmic drug treatment [41, 42]. Interestingly, among different species, the cardiac uptake mechanism of ${ }^{18} \mathrm{~F}-\mathrm{L} M I 1195$ demonstrated significant variability. In contrast to the results obtained above, cardiac uptake of ${ }^{18}$ F-LMI1195 in rats was significantly inhibited by phenoxybenzamine instead of desipramine, suggesting ${ }^{18} \mathrm{~F}$-LMI1195 undergoes uptake-2 mechanism and is consistent with the rat heart where this is the dominant mechanism [43].

${ }^{18} \mathrm{~F}-\mathrm{LM} 11195$ was recently evaluated in a phase 1 clinical trial involving 12 healthy volunteers. Experimental data regarding human safety, whole-organ (myocardial, lung, liver and blood pool uptake) biodistribution and radiation dosimetry of ${ }^{18} \mathrm{~F}-\mathrm{LMI} 1195$ were performed [44]. The results are encouraging: no adverse effects due to ${ }^{18} \mathrm{~F}-\mathrm{LMI} 1195$ were observed; relative quick blood, lung and liver clearance compared to over 4 hours' stable myocardial uptake, providing good target-to-background ratios for cardiac imaging (Figure 3). These preliminary results, similar to ${ }^{123}$ I-MIBG and ${ }^{11} \mathrm{C}-\mathrm{HED}$, suggest favorable dosimetry with high resolution imaging when applying ${ }^{18}$ F-LMI1195.

Although sympathetic nervous tracers like ${ }^{123}$ I-MIBG and ${ }^{11} \mathrm{C}-\mathrm{HED}$ are under intense investigation, the abilities of these compounds to provide accurate measurements of cardiac nerve density are limited due to their rapid NE transport rates. Therefore, a set of compounds with phenethylguanidine structures, similar to ${ }^{123}$ I-MIBG were synthesized and reported [45]. Among them, ${ }^{18} \mathrm{~F}-4 \mathrm{~F}-\mathrm{MHPG}$ (Figure 2) is an interesting radiotracer, owing to the fact that its special kinetic properties are favorable for quantifying regional nerve density with PET and tracer kinetic analysis. Some of the above compounds demonstrate slower uptake by the NE transporter compared to ${ }^{123}$ I-MIBG or ${ }^{11} \mathrm{C}-\mathrm{HED}$, and may therefore provide additional kinetic information beyond conventional imaging agents [46].

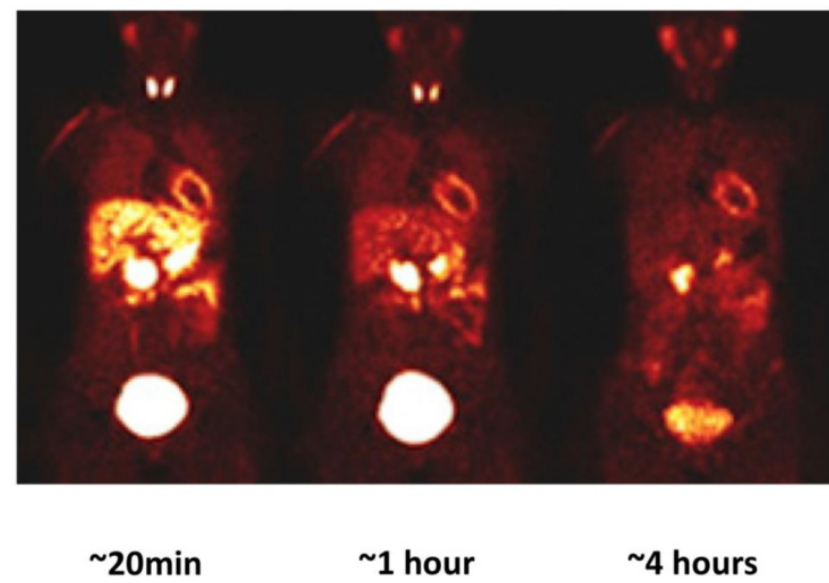

Figure 3. Whole-body ${ }^{18} \mathrm{~F}$-LMI1195 coronal images at mid-myocardial level in human volunteers. It demonstrated favorable kinetics for cardiac imaging: myocardial activity remained stable over 4 hours, with favorable heart-to lung and heart-to-liver ration over the same period. ${ }^{18} \mathrm{~F}$-LIM1 195 is rapidly cleared from circulation. Modified from original figure in reference [44].

It is noteworthy, when applying ${ }^{123}$ I-MIBG,

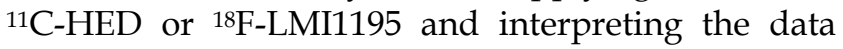
achieved, the animal model that is used for the experiment should be considered carefully, due to different uptake- 1 and -2 mechanisms presented in distinct species. Cardiac uptake-2 activity is important in the rat, cat and dog, but poorly expressed in the rabbit [47]. As a result, MIBG can be a good substrate for uptake-2 in rat heart, but will not localize in patients because of the negligibility of uptake- 2 in human [48]. By contrast, HED is a poor substrate for uptake-2 [49]. Similarly, LMI1195 shows high selectivity to neuronal uptake-1 both in rabbit and human due to the dominancy of this transporter. But in other animal species, such as rats, LMI1195 should be used cautiously [42, 43].

Postsynaptic sympathetic nervous function, alpha and beta adrenoreceptors, are also important elements in the sympathetic nervous system and seem promising for functional imaging. But currently, only a few beta-adrenoceptor antagonist-derived radioligands have been extensively investigated, such as ${ }^{11} \mathrm{C}-\mathrm{CGP} 12177$ and ${ }^{11} \mathrm{C}-\mathrm{CGP} 12388$ [50]. ${ }^{11} \mathrm{C}-\mathrm{CGP} 12177$, being derived from the beta-receptor antagonist ${ }^{3} \mathrm{H}-\mathrm{CGP} 12177$, was reported for cardiac PET imaging due to its high hydrophilicity and affinity to beta-adrenoceptor (Figure 2) [51]. It proved the possibility of investigating changes of beta-receptor density in patients, in a condition such as myocardial ischemia [51]. Moreover, it is proved to be an indicator of post-synaptic function in congestive heart failure (CHF) patients [52]. In a study involving ten patients 
with idiopathic dilated cardiomyopathy (IDC), baseline myocardial beta-receptor density estimated by ${ }^{11}$ C-CGP12177 PET was compared with changes of LVEF. The receptor density significantly correlated with delta changes of LVEF by beta-blocker carvedilol as well as plasma NE, which indicates the advantage of applying beta-receptor PET tracer for guidance of therapeutic practice [53].

The isopropyl analog of ${ }^{11}$ C-CGP 12177, i.e. ${ }^{11}$ C-CGP12388 (Figure 2), was prepared [54] and also evaluated in animals. It shows similar in vivo behavior as ${ }^{11} \mathrm{C}-\mathrm{CGP} 12177$, but is relatively easily prepared [55]. As a result, using tracer kinetic modeling, ${ }^{11} \mathrm{C}-\mathrm{CGP} 12388$ was assessed in 6 patients. The protocol with injections of high specific activity (SA), low SA and unlabeled ligands, respectively, was found to be the most sensitive protocol with regard to in vivo parameter changes, which accordingly can be used for beta-adrenoceptor density estimation as well [56]. In addition, it is proved that the receptor binding of ${ }^{11}$ C-CGP12388 was flow independent, with low nonspecific binding [57]. In accordance with the results obtained from ${ }^{11} \mathrm{C}-\mathrm{CGP} 12177$ study, the investigation involving six patients with IDC and six age-matched healthy controls using ${ }^{11} \mathrm{C}-\mathrm{CGP} 12388$ PET also indicates that it is applicable for the measurement of myocardial beta-receptor density in patients [58]. Other tracers concerning beta1-selective ligands or targeting alpha-adrenoceptors have also been reported but further assessment to confirm specificity and robustness of the assay is still needed [50].

\section{Parasympathetic nervous imaging}

In addition to sympathetic nervous imaging tracers, some radioligands have also been reported for the evaluation of the parasympathetic nervous system. But the low density and broad distribution of target receptors and rapid degradation of neurotransmitter acetylcholine make the development of ideal tracers for this system very difficult and demanding. Vesicular acetylcholine transporter vesamicol has been used to develop a series of tracers, but the low rate of specific binding in myocardium and rapid washout limited the further development of these compounds [59].

Among all parasympathetic nervous imaging, a metabolic stable $\mathrm{M}_{2}$ receptor antagonist ${ }^{11} \mathrm{C}-\mathrm{MQNB}$ was first introduced and underwent a number of studies for the visualization of cardiac muscarinic receptors [60]. It showed the distribution of muscarinic receptors in different area of human heart [61]. A mathematical model, multi-injection protocol application of ${ }^{11} \mathrm{C}-\mathrm{MQNB}$ was tested on dogs to quantify muscarinic receptors in vivo [62]. This method could be transferred into a healthy human study, whereas the complicated protocol limited broad clinical use of this tracer [63]. Even though, a study involving 20 patients with CHF has further successfully demonstrated the associated upregulation of myocardial muscarinic receptors in these patients [64]. Furthermore, applying ${ }^{11} \mathrm{C}-\mathrm{MQNB}$ PET to 11 patients few days after myocardial infarction, it was suggested that muscarinic receptor density remains within normal values in regions containing damaged tissue [65].

Not so much work has been done on the plausible assessment of parasympathetic nervous system using tracers derived from acetylcholinesterase (AChE) inhibitors. Some ${ }^{11} \mathrm{C}$-tracers were developed by Wang et al. could show rapid heart uptake and delineate the heart clearly [66]. Recently, clinically used $\mathrm{AChE}$ inhibitor derived tracer ${ }^{11} \mathrm{C}$-donepezil has been tested and proved good PET imaging tracer to quantify the parasympathetic innervation in the heart [67], which might open a gate to cardiac radionuclear imaging.

\section{Renin-angiotensin aldosterone system imaging}

In addition to tracers focusing on the autonomic nervous system, the RAS has also received attention in cardiac imaging due to the fact that it plays a very important role in left ventricular remodeling. Angiotensin II receptor antagonists were chosen to build up the non-invasive assessment of regional activation of the RAS, so as to improve the understanding of its role in remodeling and to optimize RAS-based pharmacotherapy.

The RAS is a hormonal cascade that generates angiotensin peptides and is the main regulator of blood pressure as well as fluid and electrolyte balance. When decreased intrarenal blood pressure or low sodium and chloride in the kidney are detected, renin is released. It acts on angiotensinogen produced in the liver to generate a ten amino acid oligopeptide angiotensin I. It is afterwards converted to angiotensin II through the catalysis of ACE. Angiotensin II is considered a major factor and vasoactive hormone to increase the blood pressure by stimulating the angiotensin II receptor (mainly $\mathrm{AT}_{1}$ ) [68]. Therefore, in cardiovascular diseases, such as hypertension or HF, either $\mathrm{ACE}$ or $\mathrm{AT}_{1}$ receptor antagonists are considered valuable therapeutic targets (Figure 4 ). In recent years $\mathrm{AT}_{1}$ receptor antagonists provided a more specific blockade of the RAS with virtually no agonist effect and better safety compared to ACE inhibitors [69,70]. In addition to the circulating RAS, which contributes to the systemic regulation of global cardiovascular homeostasis, the heart has an intrinsic RAS that mediates locoregional mechanisms such as interstitial fibrosis, myocyte hypertrophy and apoptosis [71]. 
Activation of the intrinsic myocardial RAS may be responsible for structural and functional changes, which are hallmarks of HF progression.

Due to the decisive role that ACE inhibitors play in cardiovascular disease treatment, it is very attractive to develop ACE inhibitor-derived tracers for monitoring of disease progress and improving drug applications. Lisinopril is a clinically used ACE inhibitor for the treatment of hypertension and CHF. It was used in ACE imaging from three different approaches: I-125 labeled benzamidine analog ${ }^{125} \mathrm{I}-351 \mathrm{~A}$ [72] and technetium-99m labeled compound 99mTc-lisinopril $[73,74]$ for SPECT imaging, as well as the F-18 labeled benzoyl analog ${ }^{18}$ F-fluorobenzoyl lisinopril [75] for PET imaging (Figure 5). While maintaining the inhibition of ACE, they all successfully visualized the distribution of ACE while blocking studies proved specificity in vivo [76,77]. An ${ }^{11} \mathrm{C}$ tracer derived from ACE inhibitor zofenopril (Figure 5) was reported by Matarrese et al. and evaluated first-hand in human. But similar to other ACE tracers, the compound accumulated mainly in the organs with high levels of ACE, like lungs and kidneys, or liver and gall bladder for metabolism reason [78]. Therefore, the usage of this tracer would be greatly limited in the human heart. By applying these tracers, despite the nonuniform binding, or distribution of ACE in heart, it might be possible to monitor myocardial ACE upregulation in the progress of $\mathrm{HF}$ and might allow the optimization of pharmacological intervention [72, 77].

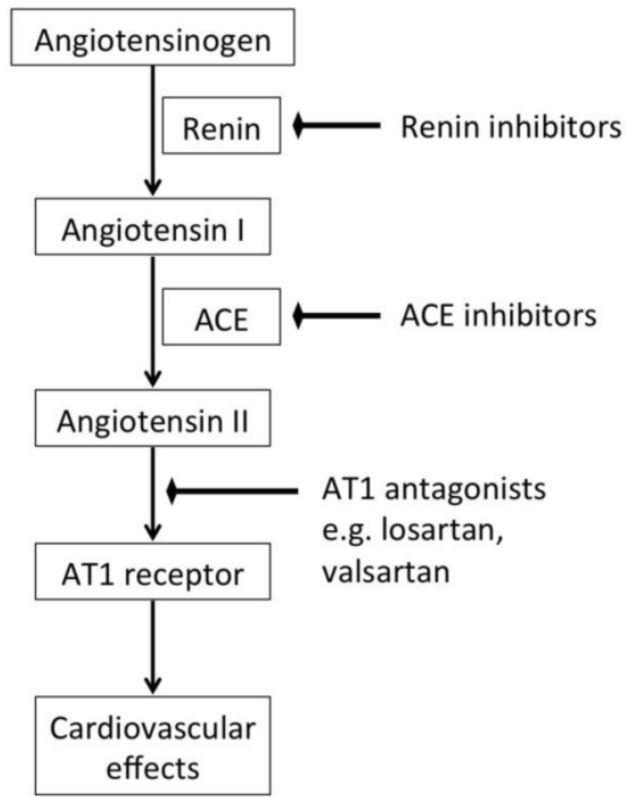

Figure 4. Simplified renin-angiotensin system and the corresponding therapeutic strategies.

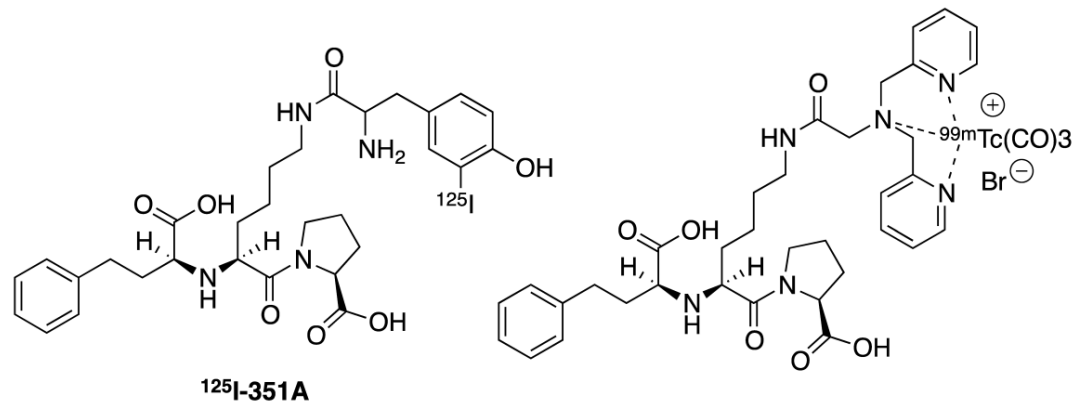<smiles>O=C(NCCCCC(NC(CCc1ccccc1)C(=O)O)C(=O)N1CCCC1C(=O)O)c1ccc(F)cc1</smiles>

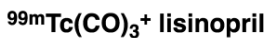<smiles>O=C(O)C(CS)N1CC([SbH])CC1C(=O)O</smiles>

${ }^{11} \mathrm{C}$-Zofenoprilat

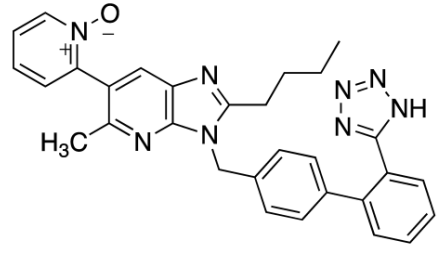

SK1080

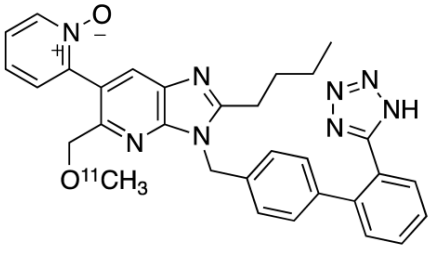

[11C]KR31173

Figure 5. Chemical structures of current radiolabeled tracers targeting RAS. 
Compound ${ }^{11} \mathrm{C}-\mathrm{KR} 31173$ shows similar binding affinity at the $\mathrm{AT}_{1}$ receptor in vitro (Figure 5) as its lead compound SK-1080, a non-peptide $\mathrm{AT}_{1}$ selective antagonist [79]. It is metabolically stable and demonstrates promising biodistribution and kinetic properties in multiple species. Ex vivo biodistribution studies in mice demonstrated specific binding rates of $80-90 \%$ in the adrenal glands, kidneys, lungs and heart. Kidney and liver uptake was observed in mice and the uptake competes with SK-1080 [80].

In a study using a rat myocardial infarction model, ${ }^{11}$ C-KR31173 was used to determine the feasibility of characterizing the presence and time course of regional myocardial $\mathrm{AT}_{1}$ receptor upregulation and the blocking efficacy of various anti-RAS drugs. Using small-animal PET, the increased uptake of ${ }^{11} \mathrm{C}-\mathrm{KR} 31173$ in the infarct area, i.e. transient regional $\mathrm{AT}_{1}$ receptor upregulation, was detected with a peak at 1-3 weeks after surgery. This effect can be completely blocked by intravenous SK-1080 as well as by using the clinical $\mathrm{AT}_{1}$ blocker valsartan instead of the ACE inhibitor enalapril, which clearly confirms the $\mathrm{AT}_{1}$ receptor-targeted imaging and provides a rationale to predict the risk for ventricular remodeling and to monitor the efficacy of anti-RAS drug therapy [81]. Healthy pig studies also demonstrated myocardial retention of ${ }^{11} \mathrm{C}-\mathrm{KR} 31173$, with regional homogeneousness and $\mathrm{AT}_{1}$ receptor specificity, as confirmed by blocking experiments (Figure 6). Furthermore, first-in-man studies were performed without adverse effects. Myocardial retention as well as regional homogeneousness of ${ }^{11} \mathrm{C}-\mathrm{KR} 31173$ in cardiac imaging was similar to pigs and stable over time yet with intense liver uptake. The myocardial retention could be selectively blocked with $\mathrm{AT}_{1}$ receptor antagonist olmesartan [82].

It is worth emphasizing here, that similar to sympathetic nervous system imaging, when applying RAS system imaging, the species difference should also be taken into account, since rat is lack of enough amount of angiotensin receptors expressed in myo-

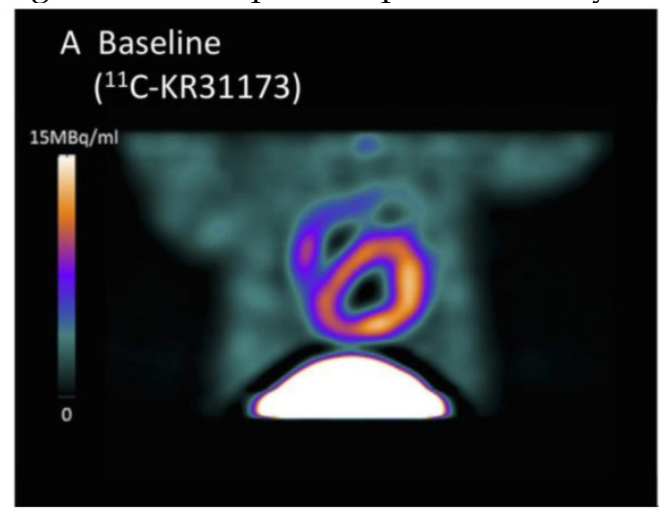

cardiocytes at physiological conditions [83], whereas it is expressed in both rabbits and humans. Those animal models using rat were applicable after myocardial infarction to visualize active myofibroblast during the course of healing process. In humans, the level of $\mathrm{AT}_{1}$ receptors in ventricular myocardium suggested to decrease in HF as shown in ex-vivo tissue experiments $[84,85]$. Further in-vivo PET imaging in HF patients may provide further insights into dynamic and regional information of $\mathrm{AT}_{1}$ receptor function.

\section{Endothelin A receptor imaging}

Endothelins (ETs) are a family of natural vasoconstricting peptides released primarily by endothelial cells. There are three isoforms of ETs: $\mathrm{ET}_{1}, \mathrm{ET}_{2}$ and $\mathrm{ET}_{3}$. Among them, $\mathrm{ET}_{1}$ is the predominant isoform affecting the cardiovascular system by stimulation of the subtype $\mathrm{A}$ receptor $\left(\mathrm{ET}_{\mathrm{A}}\right.$, a $\mathrm{G}$-protein-coupled receptor) on vascular smooth cells and subsequent vasoconstrictive effects. The stimulation of the subtype $\mathrm{B}$ receptor $\left(\mathrm{ET}_{\mathrm{B}}\right)$ by $\mathrm{ET}_{1}$ leads to the release of vasodilators such as nitric oxide. In addition, the production and release of $\mathrm{ET}_{1}$ as well as the expression of ET receptors is enhanced during HF [86]. Therefore, the use of ET receptor antagonists, mainly for $\mathrm{ET}_{\mathrm{A}}$, may have a therapeutic effect in patients with HF [87].

Carbon-11 labeled $\mathrm{ET}_{\mathrm{A}}$ and $\mathrm{ET}_{\mathrm{B}}$ receptors antagonist and peptide-based L-753037 has been synthesized (Figure 7). Small animal studies have been conducted in mice and dogs. Tracer uptake was initially much higher in liver, lungs and kidneys than in heart, yet the radioactivity remained constant in the heart for over 2 hours compared to the fast washout in other organs. In dog studies, there is also high tracer accumulation in the heart, which can be blocked by pretreatment of corresponding ET receptor antagonist L-753164 [88].

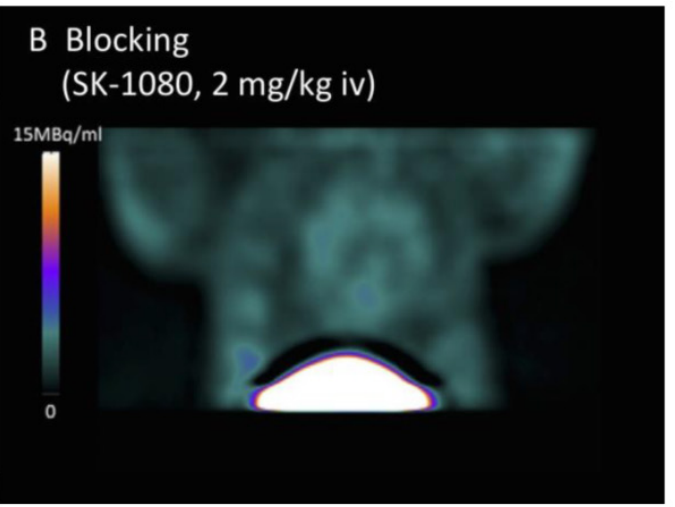

Figure 6. Stable cardiac uptake of " C-KR31173 as baseline (A) and blockade by SK-1080 (B) in healthy pig. High specific cardiac tracer accumulation was proven. Modified from original figure [82]. 


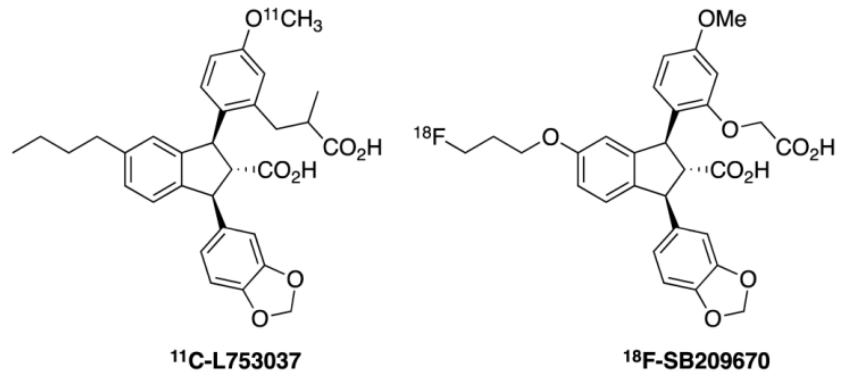

Figure 7. Radiotracers derived from non-peptide ET receptor antagonists.
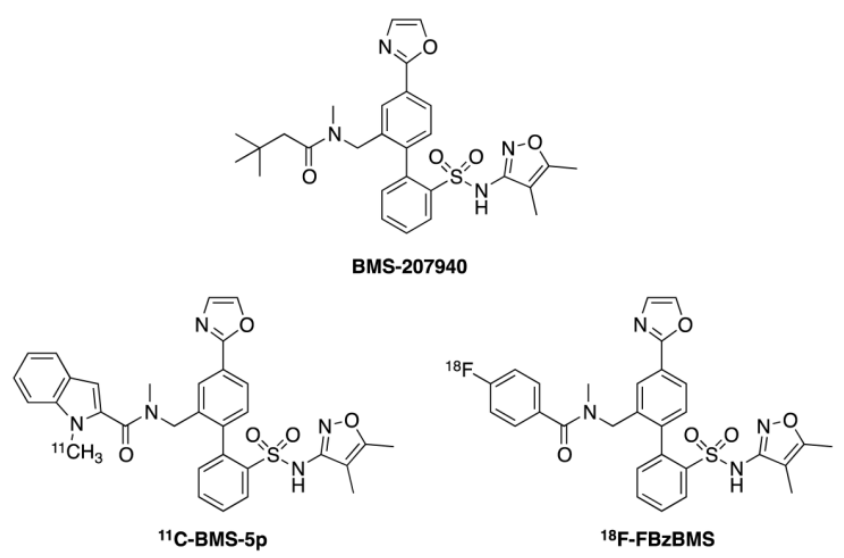

Figure 8. Chemical structures of $\mathrm{ET}_{\mathrm{A}}$ receptor radioligands.

${ }^{18} \mathrm{~F}-\mathrm{SB} 209670$ is a non-peptide ET receptor antagonist with a structure very similar to L-753037 (Figure 7). It is used to investigate pharmacokinetic properties to permit binding and imaging of ET receptors in rat hearts in vivo. This compound has been demonstrated to bind to human heart tissue with subnanomolar affinity. Rapid clearance from liver and subsequent redistribution to the small intestine was observed indicating high levels of hepatic metabolism. Despite this property, visualization of uptake in the rat heart in vivo suggests rapid and primary binding to $\mathrm{ET}_{\mathrm{A}}$ receptors [89].

Compounds ${ }^{11} \mathrm{C}-\mathrm{BMS}-5 \mathrm{p}$ and ${ }^{18} \mathrm{~F}-\mathrm{FBzBMS}$ are the ${ }^{11} \mathrm{C}$ and ${ }^{18} \mathrm{~F}$ PET radioligands targeting $\mathrm{ET}_{\mathrm{A}}$ receptor, derived from $\mathrm{ET}_{\mathrm{A}}$ antagonist BMS-207940, respectively (Figure 8). In mice, both radioligands demonstrate early uptake in liver, lungs and heart. The radioactivity in heart and lungs remain relatively stable while it decreases in the liver due to wash out. Specific binding in the heart was determined to be $63 \%$ for ${ }^{11} \mathrm{C}-\mathrm{BMS}-5 \mathrm{p}$ and $81 \%$ for ${ }^{18} \mathrm{~F}-\mathrm{FBzBMS}$. Furthermore, baboon studies demonstrate high myocardial uptake by showing $85 \%$ specific binding at $85 \mathrm{~min}$ after injection. This specific myocardial uptake can be blocked by pretreatment of BMS-207940, which represents a selective $\mathrm{ET}_{\mathrm{A}}$ receptor antagonist [90].

An in vivo study using 32 healthy rats recently confirmed cardiac uptake of ${ }^{18} \mathrm{~F}-\mathrm{FBzBMS}$, which could be blocked either by intravenous pretreatment of BMS-207940 by $93 \%$, or in a dose-dependent (5-100 $\mathrm{mg} / \mathrm{kg}$ ) partial blockade by the oral administration of clinical $\mathrm{ET}_{\mathrm{A}}$ blocker bosentan (Figure 9). The myocardial uptake of ${ }^{18} \mathrm{~F}-\mathrm{FBzBMS}$ was preserved in the infarct region from day 1 to month 6 . Ex vivo analysis also confirmed $\mathrm{ET}_{\mathrm{A}}$ receptor expression in the infarct area, where PET imaging partially overlapping with CD31 expression on endothelial cells [91].

It is worth mentioning here that positive results of the application of endothelin receptor antagonism from animal models of HF were not successfully translated into clinical practice as shown in the phase 3 clinical trial of bosentan. In this trial, treatment of chronic HF with bosentan did not reach the expected therapeutic endpoint [92]. However, the reasons might be complex and need further evaluation. In particular, the usage of radionuclide imaging becomes more important in this case; determination of optimal dose and duration of medication is needed, and so is the discovery of the physiopathological principle underlying the distinct therapeutic responses involved in post infarct remodeling. Therefore, the application of non-invasive monitoring of the endothelin system may become more important in helping researchers to explore new treatment modalities.

\section{Summary and perspective}

Personalized medicine tailors medical treatment to individual characteristics of each patient and optimize treatments to achieve maximum efficacy with minimum harm [93]. Radionuclide imaging contributes to personalized medicine in five stages: early predisposition profiling, monitoring and prevention, diagnostics, treatment selection and medication monitoring [94]. It is noteworthy, although therapeutic approaches such as ACE inhibitors and $\mathrm{AT}_{1}$ antagonists have been applied in patients for a couple of decades, the responses to the treatments are highly variable [95]. In clinical practice highest pharmaceutical doses are normally recommended, but side effects are correspondingly increasing with incremental doses. Therefore, it will be ideal to have individual optimal-effective dose determination strategies for patients by applying molecular imaging combined with specific radiotracers. Moreover, the ADMIRE-HF/HFX trial proved the extra value by incorporating the application of ${ }^{123}$ I-MIBG into the selection of appropriate candidate patients for ICD implantation. Both cost effectiveness and risk reduction in this case demonstrated the advantages of utilisation of nuclear imaging $[20,96]$. It is therefore promising to provide specific indications for drug responses and to support personalized medicine. 
A
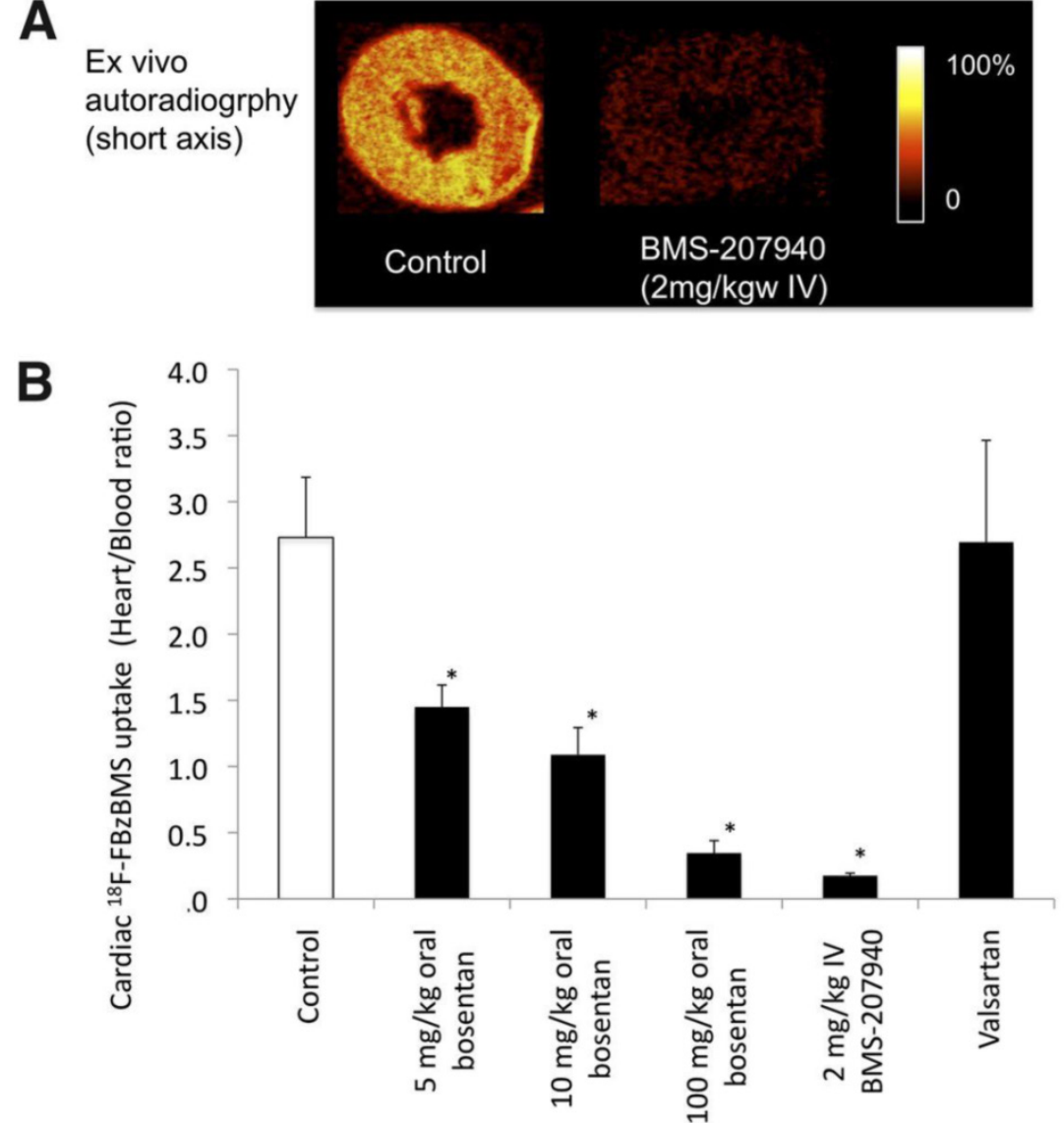

Figure 9. (A) Autoradiographic short-axis images of ${ }^{18} \mathrm{~F}-\mathrm{FBzBMS}$ in healthy rat hearts with and without $\mathrm{ET}_{\mathrm{A}}$ antagonist $\mathrm{BMS}-207940$ pretreatment. (B) Effects of medication on cardiac 18F-FBzBMS uptake. Dose dependent blockage by bosentan was shown. $* \mathrm{P}<0.001 \mathrm{vs}$. control. $\mathrm{mg} / \mathrm{kgw}=\mathrm{mg}$ per kg of body weight [91].

In addition to the aforementioned stand-alone instruments, i.e. using SPECT or PET alone, the last few years have led to the integration and spatial co-localization of morphological and functional information using hybrid imaging, e.g. SPECT/CT, PET/CT and so on. These techniques appear to be beneficial and provide superior diagnostic and prognostic information compared to previous generation imaging agents and techniques. They supply complementary morphological (from MRI or CT) and functional information at the cellular and molecular level (from SPECT or PET) in a single setting. These studies have the potential to be clinically more effective and to minimize costs. These combinations may trace signals addressing molecular and physiological aspects of disease phenotype and therapeutic effects $[97,98]$.

Cardiovascular molecular imaging, in particular targeting the neurohormonal system of the heart, is a rapidly emerging discipline promising visualization of specific molecular targets and pathways, i.e. enzymes, receptors or transporters, which precede or underlie changes in morphology, physiology and function. Particularly due to the high detection sensi- tivity, non-invasive imaging with PET (using ${ }^{11} \mathrm{C}$ or preferably ${ }^{18} \mathrm{~F}$ tracers) has become a key player in the development and introduction of novel molecular imaging approaches [99]. There are several advantages and disadvantages, which should be addressed here once again. Advantages include the great potential of cardiac imaging to aid in the discovery and development of novel therapies through improved target identification, to enhance fundamental cardiac research by visualizing cellular and subcellular targeted structures, to move forward in achieving better sensitivity and image quality as well as molecular specificity, and also to act as a key element in emerging personalized medicine by distinguishing diverse geno- and phenotypical differences between cardiac patients [99]. In the Prediction of Arrhythmic Events with Positron Emission Tomography (PAREPET) clinical study, applying three different tracers to quantify resting perfusion, NE uptake and metabolic viability, it is performed in order to identify the possible determinants to develop into sudden cardiac death $[100,101]$. However, it is also noteworthy, that although PET can achieve better imaging quality and is equipped with more radio- 
tracer options, the opportunity cost of cyclotron installation strongly limits its wide application. Furthermore PET/CT systems are more costly than standalone CT or SPECT systems. Even though these challenges exist, advances in the application of molecular imaging of neurohormonal systems may play an increasingly critical role in eventual diagnosis, prognosis and clinical treatment of cardiovascular diseases.

\section{Abbreviations}

ACE: angiotensin converting enzyme; AChE: acetylcholinesterase; ANP: atrial natriuretic peptide; $\mathrm{AT}_{1}$ : angiotensin II receptor type 1 ; $\mathrm{CHD}$ : coronary heart disease; $\mathrm{CHF}$ : congestive heart failure; COMT: catecholamine-O-methyl-transferase; CT: computed tomography; $\mathrm{EPI}$ : epinephrine; $\mathrm{ET}_{\mathrm{A}}$ : endothelin subtype $\mathrm{A}$ receptor; $\mathrm{ET}_{\mathrm{B}}$ : endothelin subtype $\mathrm{B}$ receptor; ETs: endothelins; HED: meta-hydroxyephedrine; HF: heart failure; ICD: implantable cardiac defibrillator; IDC: idiopathic dilated cardiomyopathy; LVEF: left ventricular ejection fraction; MAO: monoamine oxidase; MHPG: 3-methoxy-4-hydroxyphenylglycol; MIBG: m-iodobenzylguanidine; NE: norepinephrine; NMN: normetanephrine; NYHA: New York Heart Association; PAREPET: Prediction of Arrhythmic Events with Positron Emission Tomography; PET: positron emission tomography; PHEN: phenylephrine; RAS: renin angiotensin system; SA: specific activity; SCD: sudden cardiac death; SPECT: single photon emission computed tomography; VMAT: vesicular monoamine transporter.

\section{Competing Interests}

The authors have declared that no competing interest exists.

\section{References}

1. Chen IY, Wu JC. Cardiovascular molecular imaging: Focus on clinical translation. Circulation. 2011; 123(4): 425-43.

2. Higuchi T, Schwaiger M. Noninvasive imaging of heart failure: neuronal dysfunction and risk stratification. Heart Fail Clin. 2006; 2: 193-204.

3. Minguell ER. Clinical use of markers of neurohormonal activation in heart failure. Rev Esp Cardiol. 2004; 57(4): 347-56.

4. Ginsburg GS, Donahue MP, Newby LK. Prospects for personalized cardiovascular medicine: The impact of genomics. J Am Coll Cardiol. 2005; 46: 1615-27.

5. McMurray J, Cohen-Solal A, Dietz R, Eichhorn E, Erhardt L, Hobbs FD, Krum H, Maggioni A, McKelvie RS, Piña IL, Soler-Soler J, Swedberg K. Practical recommendations for the use of ACE inhibitors, beta-blockers, aldosterone antagonists and angiotensin receptor blockers in heart failure: Putting guidelines into practice. Eur J Heart Fail. 2005; 7(5): 710-21.

6. Roig E. Usefulness of neurohormonal markers in the diagnosis and prognosis of heart failure. Eur Heart J Suppl. 2006; 8: E12-7.

7. Triposkiadis F, Karayannis G, Giamouzis G, Skoularigis J, Louridas G, Butler J. The sympathetic nervous system in heart failure: physiology, pathophysiology, and clinical implications. J Am Coll Cardiol. 2009; 54(19): 1747-62.

8. Floras JS. Sympathetic nervous system activation in human heart failure: Clinical implications of an updated model. J Am Coll Cardiol. 2009; 54(5): 375-85.

9. Boogers MJ, Veltman CE, Bax JJ. Cardiac autonomic nervous system in heart failure: imaging technique and clinical implications. Curr Cardiol Rev. 2011; 7: 35-42.
10. Travin MI. Cardiac radionuclide imaging to assess patients with heart failure. Sem Nucl Med. 2014; doi: 10.1053/j.semnuclmed.2014.04.005.

11. Foody JM, Farrell MH, Krumholz HM. Beta-blocker therapy in heart failure: Scientific review. JAMA 2002; 287(7): 883-9.

12. Bristow MR, Saxon LA, Boehmer J, Kruger S, Kass DA, De Marco T, Carson P, DiCario L, DeMets D, White BG, DeVries DW, Feldman AM. Cardiac-resynchronization therapy with or without an implantable defibrillator in advanced chronic heart failure. N Eng J Med. 2004; 350(21): 2140-50.

13. Zineh I, Johnson JA. Pharmacogenetics of chronic cardiovascular drugs: applications and implications. Expert Opin Pharmacother. 2006; 11: 1417-27.

14. DeGeorge BR, Koch WJ. Beta blocker specificity: a building block toward personalized medicine. J Clin Invest. 2007; 117(1): 86-9.

15. Gupta M, Honos GN, Velazquez EJ, Chung N, Oigman W, Maggioni AP. Evidence for the efficacy of ARBs across the cardiovascular continuum. Curr Med Res Opin. 2010; 26: 1203-18.

16. Eisenhofer G, Smolich JJ, Cox HS, Esler MD. Neuronal reuptake of norepinephrine and production of dihydroxyphenylglycol by cardiac sympathetic nerves in the anesthetized dog. Circulation. 1991; 84: 1354-63.

17. Al-Damluji S, Krsmanovic LZ, Catt KJ. High-affinity uptake of noradrenaline in postsynaptic neurons. Br J Pharmacol. 1993; 109: 299-307.

18. Thackeray JT, Bengel FM. Assessment of cardiac autonomic neuronal function using PET imaging. J Nucl Cardiol. 2013; 20(1): 150-65.

19. Wieland DM, Wu J, Brown LE, Mangner TJ, Swanson DP, Beierwaltes WH. Radiolabeled adrenergic neuron-blocking agents: adrenomedullary imaging with [131I]iodobenzylguanidine. J Nucl Med. 1980; 21(4): 349-53.

20. Jacobson AF, Senior R, Cerqueira MD, Wong ND, Thomas GS, Lopez VA, Agostini D, Weiland F, Chandna H, Narula J. Myocardial iodine-123 meta-iodobenzylguanidine imaging and cardiac events in heart failure. Results of the prospective ADMIRE-HF (AdreView Myocardial Imaging for Risk Evaluation in Heart Failure) study. J Am Coll Cardiol. 2010; 55(20): 2212-21.

21. Arora R, Ferrick KJ, Nakata T, Kaplan RC, Rozengarten M, Latif F, Ng K, Marcano V, Heller S, Fisher JD, Travin MI. I-123 MIBG imaging and heart rate variability analysis to predict the need for an implantable cardioverter defibrillator. J Nucl Med. 2003; 10(2): 121-31.

22. Gerson MC, McGuire N, Wagoner LE. Sympathetic nervous system function as measured by I-123 metabenzylguanidine predicts transplant-free survival in heart failure patients with iodopathic dilated cardiomyopathy. J Card Fail. 2003; 9(5): 384-91.

23. Tamaki S, Yamada T, Okuyama Y, Morita T, Sanada S, Tszkamoto Y, Masuda M, Okuda K, Iwasaki Y, Yasui T, Hori M, Fukunami M. Cardiac iodine-123 metaiodobenzylguanidine imagine predicts sudden cardiac death independently of left ventricular ejection fraction in patients with chronic heart failure and left ventricular systolic dysfunction: results from a comparative study with signal-averaged electrocardiogram, heart rate variability, and QT dispersion. J Am Coll Cardiol. 2009; 53(5): 426-35.

24. Boogers MJ, Borleffs CJ, Henneman MM, van Bommel RJ, van Ramshorst J, Boersma E, Dibbets-Schneider P, Stokkel MP, van der Wall EE, SChalij MJ, Bax JJ. Cardiac sympathetic denervation assessed with 123-iodine metaiodobenzylguanidine imaging predicts ventricular arrhythmias in implantable cardioverter-defibrillator patients. J Am Coll Cardiol. 2010; 55(24): 2769-77.

25. Kelesidis I, Travin MI. Use of cardiac radionuclide imaging to identify patients at risk for arrhythmic sudden cardiac death. J Nucl Med. 2012; 19(1): 142-52.

26. Merlet P, Benvenuti C, Moyse D, Pouillart F, Dubois-Randé JL, Duval AM, Loisance D, Castaigne A, Syrota A. Prognostic value of MIBG imaging in idiopathic dilated cardiomyopathy. J Nucl Med. 1999; 40(6): 917-23.

27. Cohen_Solal A, Esanu Y, Logeart D, Pessione F, Dubois C, Dreyfus G, Gourgon $R$, Merlet P. Cardiac metaiodobenzylguanidine uptake in patients with moderate chronic heart failure: Relationship with peak oxygen uptake and prognosis. J Am Coll Cardiol. 1999; 33(3): 759-66.

28. Anastasiou-Nana MI, Terrovitis JV, Athanasoulis T, Karaloizos L, Geramoutsos A, Pappa L, Tsagalou EP, Efentakis S, Nanas JN. Prognostic value of iodine-123-metaiodobenzylguanidine myocardial uptake and heart rate variability in chronic congestive heart failure secondary to ischemic or idiopathic dilated cardiomyopathy. Am J Cardiol. 2005; 96(3): 427-31.

29. Momose M, Kobayashi H, Iguchi N, Matsuda N, Sakomura Y, Kasanuki H, Kusakabe K, Okawa T. Comparison of parameters of ${ }^{123}$ I-MIBG scintigraphy for predicting prognosis in patients with dilated cardiomyopathy. Nucl Med Commun. 1999; 20(6): 529-35

30. Ogita $H$, Shimonagata $T$, Fukunami $M$, Kumagai $K$, Yamada $T$, Asano $Y$, Hirata A, Asai M, Kusuoka H, Hori M, Hoki N. Prognostic significance of cardiac ${ }^{123}$ I metaiodobenzylguanidine imaging for mortality and morbidity in patients with chronic heart failure: A prospective study. Heart. 2001; 86(6): 656-60.

31. Yamada T, Shimonagata T, Fukunami M, Kumagai K, Ogita H, Hirata A, Asai M, Makino N, Kioka H, Kusuoka H, Hori M, Hoki N. Comparison of the prognostic value of cardiac iodine-123 metaiodobenzylguanidine imaging and heart rate variability in patients with chronic heart failure: A prospective study. J Am Coll Cardiol. 2003; 41(2): 231-8.

32. Verberne HJ, Brewster LM, Somsen GA, van Eck-Smit BL. Prognostic value of myocardial ${ }^{123}$ I-metaiodobenzylguanidine (MIBG) parameters in patients with heart failure: A systematic review. Eur Heart J. 2008; 29(9): 1147-59.

33. Stefanelli A, Treglia G, Bruno I, Rufini V, Giordano A. Pharmacological interference with 123I-metaiodobenzylguanidine: a limitation to developing cardiac innervation imaging in clinical practice? Eur Rev Med Pharmacol Sci. 2013; 17: 1326-33. 
34. Schwaiger M, Kalff V, Rosenspire K, Haka MS, Molina E, Hutchins GD, Deeb M, Wolfe E, Wieland DM. Noninvasive evaluation of sympathetic nervous system in human heart by positron emission tomography. Circulation. 1990; 82(2): 457-64.

35. Matsunari I, Aoki H, Nomura Y, Takeda N, Chen WP, Taki J, Nakajima K, Nekolla SG, Kinuya S, Kajinami K. Iodine-123 metaiodobenzylguanidine imaging and carbon-11 hydroxyephedrine positron emission tomography compared in patients with left ventricular dysfunction. Circ Cardiovasc Imaging. 2010; 3(5): 595-603

36. Thackeray JT, Renaud JM, Kordos M, Klien R, Dekemp RA, Beanlands RS, DaSilva JN. Test-retest repeatability of quantitative cardiac 11C-meta-hydroxyephedrine measurements in rats by small animal positron emission tomography. Nucl Med Biol. 2013; 40(5): 676-81.

37. Del Rosario RB, Jung YW, Caraher J, Chakraborty PK, Wieland DM. Synthesis and preliminary evaluation of $\left.{ }^{[11} \mathrm{C}\right]-(-)$-phenylephrine as a functional heart neuronal PET agent. Nucl Med Biol. 1996; 23(5): 611-6.

38. Raffel DM, Corbett JR, del Rosario RB, Mukhopadhyay SK, Gildersleeve DL, Rose P, Wieland DM. Sensitivity of $\left.{ }^{11} \mathrm{C}\right]$ phenylephrine kinetics to monoamine oxidase activity in normal human heart. J Nucl Med. 1999; 40(2): 232-8.

39. Münch G, Nguyen NT, Nekolla S, Ziegler S, Muzik O, Chakraborty P, Wieland DM, Schwaiger M. Evaluation of sympathetic nerve terminals with [(11)C]epinephrine and [(11)C]hydroxyephedrine and positron emission tomography. Circulation. 2000; 101: 516-23.

40. Yu M, Bozek J, Lamoy M, Guaraldi M, Silva P, Kagan M, Yalamanchili P, Onthank D, Mistry M, Lazewatsky J, Broekema M, Radeke H, Purohit A, Cdebaca M, Azure M, Cesati R, Casebier D, Robinson SP. Evaluation of LMI1195, a novel ${ }^{18}$ F-labeled cardiac neuronal PET imaging agent, in cells and animal models. Circ Cardiovasc Imaging. 2011; 4: 435-43.

41. Yu M, Bozek J, Lamoy M, Kagan M, Benites P, Onthank D, Robinson SP. LMI1195 PET imaging in evaluation of regional cardiac sympathetic denervation and its potential role in antiarrhythmic drug treatment. Eur J Nucl Med Mol Imaging. 2012; 39(12): 1910-9.

42. Yu M, Bozek J, Kagan M, Guaraldi M, Silva P, Azure M, Onthank D, Robinson SP. Cardiac retention of PET neuronal imaging agent LMI1195 in different species: Impact of norepinephrine uptake- 1 and -2 transporters. Nucl Med Bio. 2013; 40(5): 682-8.

43. Higuchi T, Yousefi BH, Kaiser F, Gärtner F, Rischpler C, Reder S, Yu M, Robinson S, Schwaiger M, Nekolla SG. Assessment of the ${ }^{18} \mathrm{~F}-$ labeled PET tracer LMI1195 for imaging norepinephrine handling in rat hearts. J Nucl Med. 2013; 54(7): 1142-6.

44. Sinusas AJ, Lazewatsky J, Brunetti J, Heller G, Srivastava A, Liu YH, Sparks R, Puretskiy A, Lin SF, Crane P, Carson RE, Lee LV. Biodistribution and radiation dosimetry of LMI1195: First-in-human study of a novel 18F-labeled tracer for imaging myocardial innervation. J Nucl Med. 2014; 55(9): 1445-51.

45. Raffel DM, Jung YW, Gildersleeve DL, Sherman PS, Moskwa JJ, Tluczek LJ, Chen W. Radiolabeled phenethylguanidines: novel imaging agents for cardiac sympathetic neurons and adrenergic tumors. J Med Chem. 2007; 50(9): 2078-88

46. Jang KS, Jung YW, Gu G, Koeppe RA, Sherman PS, Quesada CA, Raffel DM. 4-[18F]Fluoro-m-hydroxyphenethylguanidine: a radiopharmaceutical for quantifying regional cardiac sympathetic nerve density with positron emission tomography. J Med Chem. 2013; 56(18): 7312-23.

47. Welch MJ, Eckelman WC. Targeted molecular imaging (Imaging in medical diagnosis and therapy). UK and USA: CRC Press; 2012.

48. Glowniak I, Turner F, Gray L, Palac R, Laguna-Solar M, Woddward W. Iodine-123 metaiodobenzylguanidine imaging of the heart in idiopathic congestive cardiomyopathy and cardiac transplants. J Nucl Med. 1989; 30: 1182-91.

49. DeGrado TR, Zalutsky MR, Vaidyanathan G. Uptake mechanisms of meta-[123I]iodobenzylguanidine in isolated rat heart. Nucl Med Biol. 1995; 22: $1-12$.

50. Riemann B, Schäfers M, Law MP, Wichter T, Schober O. Radioligands for imaging myocardial alpha- and beta-adrenoceptors. Nuklearmedizin. 2003; 42(1): 4-9.

51. Delforge J, Syrota A, Lancon JP, Nakajima K, Loc'h C, Janier M, Vallois JM, Cayla J, Crouzel C. Cardiac beta-adrenergic receptor density measured in vivo using PET, CGP12177, and a new graphical method. J Nucl Med. 1991; 32: 739-48.

52. Link JM, Stratton JR, Levy W, Poole JE, Shoner SC, Stuetzle W, Caldwell JH. PET measures of pre- and post-synaptic cardiac beta adrenergic function. Nucl Med Biol. 2003; 30(8): 795-803

53. Naya M, Tsukamoto T, Morita K, Katoh C, Nishijima K, Komatsu H, Yamada S, Kuge Y, Tamaki N, Tsutsui H. Myocardial beta.adrenergic receptor density assessed by ${ }^{11} \mathrm{C}-\mathrm{CGP} 12177$ PET predicts improvement of cardiac function after carvedilol treatment in patients with idiopathic dilated cardiomyopathy. J Nucl Med. 2009; 50(2): 220-5

54. Elsinga PH, van Waarde A, Jaeggi KA, Schreiber G, Heldoorn M, Vaalburg W. Synthesis and Evaluation of (S)-4-(3-(2'-[11C]Isopropylamino)-2hydroxypropoxy)-2H-benzimidazol-2-one $\left((S)-{ }^{11} \mathrm{C}\right] \mathrm{CGP}{ }^{12388)}$ and (S)-4-(3-((1'-[18F]Fluoroisopropyl)amino)-2-hydroxypropoxy)-2H-benzimidazo 1-2-one ((S)- [ ${ }^{18}$ F]Fluoro-CGP 12388) for Visualization of $\beta$-Adrenoceptors with Positron Emission Tomography. J Med Chem. 1997; 40(23): 3829-35.

55. van Waarde A, Elsinga PH, Doze P, Heldoom M, Jaeggi KA, Vaalburg W. A novel $\beta$-adrenoceptor ligand for positron emission tomography: Evaluation in experimental animals. Eur J Pharmacol. 1998; 343(2-3): 289-96.
56. Doze P, Elsinga PH, van Waarde A, Pieterman RM, Pruim J, Vaalburg W, Willemsen AT. Quantification of beta-adrenoceptor density in the human heart with $(S)$-[11C]CGP 12388 and a tracer kinetic model. Eur J Nucl Med Mol Imaging. 2002; 29(3): 295-304

57. Momose M, Reder S, Raffel DM, Watzlowik P, Wester HJ, Nguyen N, Elsinga $\mathrm{PH}$, Bengel FM, Remien J, Schwaiger M. Evaluation of cardiac beta-adrenoreceptors in the isolated perfused rat heart using (S)-11C-CGP12388. J Nucl Med. 2004; 45(3): 471-7.

58. de Jong RM, Willemsen AT, Slart RH, Blanksma PK, van Waarde A, Cornel JH, Vallburg W, van Veldhuisen DJ, Elsinga PH. Myocardial bet-adrenoceptor downregulation in idiopathic dilated cardiomyopathy measured in vivo with PET using the new radioligand (S)-[11C]CGP12388. Eur J Nucl Med Mol Imaging. 2005; 32(4): 443-7.

59. DeGrado TR, Mulholland GK, Wieland DM, Schwaiger M. Evaluation of $(-)[18$ F $]$ fluoroethoxybenzovesamicol as a new PET tracer of cholinergic neurons of the heart. Nucl Med Biol. 1994; 21: 189-95.

60. Syrota A, Paillotin G, Davy JM, Aumont MC. Kinetics of in vivo binding of antagonist to muscarinic cholinergic receptor in the human heart studied by positron emission tomography. Life Sci. 1984; 35: 937-45.

61. Syrota A, Comar D, Paillotin G, Davy JM, Aumont MC, Stulzaft O, Maziere B. Muscarinic cholinergic receptor in the human heart evidenced under physiological conditions by positron emission tomography. Proc Natl Acad Sci USA. 1985; 82(2): 584-8.

62. Delforge J, Janier M, Syrota A, Crouzel C, Vallois JM, Cayla J, Lançon JP, Mazoyer BM. Noninvasive quantification of muscarinic receptors in vivo with positron emission tomography in the dog heart. Circulation. 1990; 82: 1494-504.

63. Delforge J, Le Guludec D, Syrota A, Bendriem B, Crouzel C, Slama M, Merlet P. Quantification of myocardial muscarinic receptors with PET in humans. J Nucl Med. 1993; 34(6): 981-91.

64. Le Guludec D, Cohen-Solal A, Delforge J, Delahaye N, Syrota A, Merlet P. Increased myocardial muscarinic receptor density in idiopathic dilated cardiomyopathy: An in vivo PET study. Circulation. 1997; 96(10): 3416-22.

65. Mazzadi AN, Pineau J, Costes N, Le Bars D, Bonnefoi F, Croisille P, Porcher R, Chevalier P. Muscarinic receptor upregulation in patients with myocardial infarction: A new paradigm. Circ Cardiovasc Imaging. 2009; 2(5): 365-72.

66. Wang JQ, Miller MA, Fei X, Stone KL, Lopshire JC, Groh WJ, Zipes DP, Hutchins GD, Zheng $\mathrm{OH}$. Facile synthesis and initial PET imaging of novel potential heart acetylcholinesterase imaging agents [ $\left.{ }^{11} \mathrm{C}\right]$ pyridostigmine and its analogs. Nucl Med Biol. 2004; 31(7): 957-64.

67. Gjerløff T, Jakobsen S, Nahimi A, Munk OL, Bender D, Alstrup AKO, Vase $\mathrm{KH}$, Hansen SB, Brooks DJ, Borghammer P. In vivo imaging of human acetylcholinesterase density in peripheral organs using ${ }^{11} \mathrm{C}$-donepezil: Dosimetry, biodistribution, and kinetic analyses. J Nucl Med. 2014; 55(11): 1818-24.

68. Ferrario CM. Role of angiotensin II in cardiovascular disease - Therapeutic implications of more than a century of research. J Renin Angiotensin Aldosterone Syst. 2006; 7(1): 3-14

69. Anavekar NS, Solomon SD. Angiotensin II receptor blockade and ventricular remodeling. J Renin Angiotensin Aldosterone Syst. 2005; 6: 43-8.

70. Ma TKW, Kam KKH, Yan BP, Lam YY. Renin-angiotensin-aldosterone system blockade for cardiovascular diseases: Current status. Br J Pharmacol. 2010; 160: 1273-92.

71. Sun Y. Intracardiac renin-angiotensin system and myocardial repair/remodelling following infarction. J Mol Cell Cardiol. 2010; 48: 483-9.

72. Schunkert H, Jackson B, Tang SS, Schoen FJ, Smits JF, Apstein CS, Lorell BH. Distribution and functional significance of cardiac angiotensin converting enzyme in hypertrophies rat hearts. Circulation. 1993; 87(4): 1328-39.

73. Femia F, Maresca K, Joyal J, Barrett J, Coleman T, Aras O, Messina S, Eckelman W, Dilsizian V, Babich J. Synthesis and evaluation of radioligands for angiotensin converting enzyme (ACE) imaging. J Nucl Med. 2006; 47(S1): 260P

74. Femia FJ, Maresca KP, Hillier SM, Zimmerman CN, Joyal JL, Barett JA, Aras O, Dilsizian V, Eckelman WC, Babich JW. Synthesis and evaluation of a series of ${ }_{99 \mathrm{~m}} \mathrm{Tc}(\mathrm{CO})_{3}{ }^{+}$lisinopril complexes for in vivo imaging of angiotensin-converting enzyme expression. J Nucl Med. 2008; 49(6): 970-7.

75. Lee YHC, Kiesewetter DO, Lang L, Jagoda EM, Shirani J, Dilsizian V, Eckelman WC. Synthesis of $4-\left[{ }^{18} \mathrm{~F}\right]$ fluorobenzoyllisinopril: A radioligand for angiotensin converting enzyme (ACE) imaging with positron emission tomography. J Labelled Comp Radiopharm. 2001; 44(S1): S268-70.

76. Shirani J, Loredo ML, Eckelman WC, Jagoda EM, Dilsizian V. Imaging the renin-angiotensin-aldosterone system in the heart. Curr Heart Fail Rep. 2005; 2(2): 78-86.

77. Dilsizian V, Zynda TK, Petrov A, Ohshima S, Tahara N, Haider N, Donohue A, Aras O, Femia FJ, Hillier SM, Joyal JL, Wong ND, Coleman T, Babich JW, Narula J. Molecular imaging of human ACE-1 expression in transgenic rats. JACC: Cardiovasc Imaging. 2012; 5(4): 419-21.

78. Matarrese M, Salimbeni A, Turolla EA, Turozzi D, Moresco RM, Poma D, Magni F, Todde S, Rossetti C, Sciarrone MT, Bianchi G, Kienle MG, Fazio F. ${ }^{11} \mathrm{C}$-Radiosynthesis and preliminary human evaluation of the disposition of the ACE inhibitor [11C]zofenoprilat. Bioorg Med Chem. 2004; 12(3): 603-11.

79. Mathews WB, Yoo SE, Lee SH, Scheffel U, Rauseo PA, Zober TG, Gocco G, Sandberg K, Ravert HT, Dannals RF, Szabo Z. A novel radioligand for imaging the $\mathrm{AT}_{1}$ angiotensin receptor with PET. Nucl Med Bio. 2004; 31(5): 571-4.

80. Zober TG, Mathews WB, Seckin E, Yoo SE, Hilton J, Xia J, Sandberg K, Ravert HT, Dannals RF, Szabo Z. PET imaging of the $\mathrm{AT}_{1}$ receptor with [11C]KR31173. Nucl Med Bio. 2006; 33: 5-13. 
81. Higuchi T, Fukushima K, Xia J, Mathews WB, Lautamäki R, Bravo PE, Javadi MS, Dannals RF, Szabo Z, Bengel FM. Radionuclide imaging of angiotensin II type 1 receptor upregulation after myocardial ischemia-reperfusion injury. J Nucl Med. 2010; 51(12): 1956-61.

82. Fukushima K, Bravo PE, Higuchi T, Schuleri KH, Lin X, Abraham MR, Xia J, Mathews WB, Dannals RF, Lardo AC, Szabo Z, Bengel FM. Molecular hybrid positron emission tomography/computed tomography imaging of cardiac angiotensin II type 1 receptors. J Am Coll Cardiol. 2012; 60(24): 2527-34.

83. Busche S, Gallinat S, Bohle RM, Reinecker A, Seebeck J, Franke F, Fink L, Zhu $M$, Sumners C, Unger T. Expression of angiotensin AT1 and AT2 receptors in adult rat cardiomyocytes after myocardial infarction: A single-cell reserve transcriptase-polymerase chain reaction study. Am J Pathol. 2000; 157(2): 605-11.

84. Regitz-Zagrosek V, Friedel N, Heymann A, Bauer P, Neuss M, Rolfs A, Steffen C, Hildebrandt A, Hetzer R, Fleck E. Regulation, chamber localization, and subtype distribution of angiotensin II receptors in human hearts. Circulation. 1995; 91: 1461-71.

85. Haywood GA, Gullestad L, Katsuya T, Hutchinson HG, Pratt RE, Horiuchi M, Fowler MB. $\mathrm{AT}_{1}$ and $\mathrm{AT}_{2}$ angiotensin receptor gene expression in human heart failure. Circulation. 1997; 95: 1201-6.

86. Ohkita M, Tawa M, Kitada K, Matsumura Y. Pathophysiological roles of endothelin receptors in cardiovascular diseases. J Pharmacol Sci. 2012; 119(4): 302-13.

87. Nasser SA, El-Mas MM. Endothelin $\mathrm{ET}_{\mathrm{A}}$ receptor antagonism in cardiovascular disease. Eur J Pharmacol. 2014; 737: 210-3.

88. Aleksic S, Szabo Z, Scheffel U, Ravert HT, Mathews WB, Kerenyi L, Rauseo PA, Gibson RE, Burns HD, Dannals RF. In vivo labeling of endothelin receptors with [C-11]L-753,037: study in mice and a dog. J Nucl Med. 2001; 42(8): 1274-80.

89. Johnström P, Fryer TD, Richards HK, Barret O, Clark JC, Ohlstein EH, Pickard JD, Davenport AP. In vivo imaging of cardiovascular endothelin receptors using the novel radiolabelled antagonist [ $\left.{ }^{18} \mathrm{~F}\right]-\mathrm{SB} 209670$ and positron emission tomography (microPET). J Cardiovasc Pharmacol. 2004; 44(Suppl 1): S34-8.

90. Mathews WB, Murugesan N, Xia J, Scheffel U, Hilton J, Ravert HT, Dannals RF, Szabo Z. Synthesis and in vivo evaluation of novel PET radioligands for imaging the endothelin-A receptor. J Nucl Med. 2008; 49: 1529-36.

91. Higuchi T, Rischpler C, Fukushima K, Isoda T, Xia J, Javadi MS, Szabo Z, Dannals RF, Mathews W, Bengel FM. Targeting of endothelin receptors in the healthy and infracted rat heart using the PET tracer ${ }^{18 F-F B z B M S . ~ J ~ N u c l ~ M e d . ~}$ 2013; 54(2): 277-82.

92. Kalra PR, Moon JC, Coats AJ. Do results of the ENABLE (Endothelin Antagonist Bosentan for Lowering Cardiac Events in Heart Failure) study spell the end for non-selective endothelin antagonism in heart failure? Int J Cardiol. 2002; 85(2-3): 195-7.

93. Sala E, Vargas HA, Donati OF, Weber WA, Hricak H. Role of molecular imaging in the era of personalized medicine: A review. Functional Imaging in Oncology, 2014;: 43-58. DOI: 10.1007/978-3-642-40412-2_3.

94. Pither R. PET and the role of in vivo molecular imaging in personalized medicine. Expert Rev Mol Diagn. 2003; 3(6): 703-13.

95. Schilders JE, Wu H, Boomsma F, van den Meiracker AH, Danser AH. Renin-angiotensin system phenotyping as a guidance toward personalized medicine for ACE inhibitors: can the response to ACE inhibition be predicted on the basis of plasma renin or ACE? Cardiovasc Drugs Ther. 2014; 28(4): 335-45.

96. O'Day K, Levy W, Johnson M, Jacobson A. Screening implantable cardioverter defribrillator eligible heart failure patients with I-123 metaiodobenzylguanidine imaging versus no screening: An economic model comparing costs and outcomes. J Am Coll Cardiol. 2014;63(12_S). doi: 10.1016/S0735-1097(14)61119-0.

97. Higuchi T, Nekolla SG, Jankaukas A, Weber AW, Huisman MC, Reder S, Ziegler SI, Schwaiger M, Bengel FM. Characterization of normal and infarcted rat myocardium using a combination of small-animal PET and clinical MRI. J Nucl Med. 2007; 48(2): 288-94

98. Gaemperli O, Bengel FM, Kaufmann PA. Cardiac hybrid imaging. Eur Heart J. 2011; 32: 2100-8.

99. Bengel FM, Higuchi T, Javadi MS, Lautamäki R. Cardiac positron emission tomography. J Am Coll Cardiol. 2009; 54(1): 1-15.

100. Fallavollita JA, Luisi AJ Jr, Michalek SM, Valverde AM, deKamp RA, Haka MS, Hutson AD, Canty JM Jr. Prediction of arrhythmic events with positron emission tomography: PAREPET study design and methods. Contemp Clin Trials. 2006; 27(4): 374-88.

101. Fallavollita J, Heavey BM, Baldwa S, Mashtare TL Jr, Hutson AD, Sajjad M, deKemp RA, Curtis AB, Cain ME, Canty JM Jr. Volume of denervated myocardium is a novel predictor of VT/VF: Prediction of arrhythmic events with positron emission tomography (PAREPET) study (abstract). Heart Rhythm. 2012; 9(9): 1578. 